\title{
A Hybrid Model of Flooding of the Ro-Ro Ships in Damaged Conditions
}

\author{
M.K. Gerigk \\ Gdansk University of Technology, Gdańsk, Poland \\ J. Jachowski \\ Gdynia Maritime University, Gdynia, Poland \\ J. Sargun \\ Gdansk University of Technology, Gdańsk, Poland
}

\begin{abstract}
The paper presents some results on investigations concerning development of a hybrid model for assessment of performance of the ro-ro ships in damaged conditions. The model is devoted towards assessing the performance of the damaged ro-ro ships at the preliminary stage of design. The key problems associated with preparing of such the model are associated with working out a method of assessment of the damaged roro ships performance, investigating all the phenomena which associated with the flooding process of the damaged ro-ro ships and preparing the model itself. Introducing the method of assessment of the damaged roro ships performance it has been assumed that there is a dependence between the arrangement of internal spaces of a ro-ro ship and flooding process. The major phenomena which have been decided to take into account when considering flooding of the ro-ro ships are the flooding understood as the flow of external water into the data damaged compartment, impact of the flooding water on the ship structure and damaged ro-ro ship motion. Knowing the damaged ro-ro ship motion characteristics in time domain it is relatively easy to assess the damaged ro-ro ship performance according to the heeling angle and assess the ro-ro ship design according to the data arrangement of internal spaces. The last research issue is to investigate if the proposed model may be appropriate tool for assessing the performance of the ro-ro ships in damaged conditions at the preliminary stage of design. The aim of this paper is to show how to incorporate the dynamics of the damaged ro-ro ships when assessing the ship performance and safety at the preliminary stage of design. The basic information on the model for estimation of the damaged ro-ro ship behavior during the flooding process is presented. The complexity of this model is shown depending on the approach applied to consider the flooding process itself. The model is devoted towards assessment of performance of the damaged ro-ro ships and it is still under the development according to a Ph.D. research at the Faculty of Mechanical Engineering Gdańsk University of Technology.
\end{abstract}

\section{INTRODUCTION}

The aim of this paper is to show how the major problems were solved as the research aim is to incorporate the dynamics of the damaged ro-ro ships during assessing the ship performance and safety at the preliminary stage of design.
The contribution of the paper is connected with presenting some information on development of a new model for assessment of performance of the ro-ro ships in damaged conditions. The research is a step forward regarding the research which was conducted at the Gdańsk University of Technology between 2007-2010 and then from 2010 to 2012 (Gerigk 2010, Gerigk 2012, Gerigk 2014a). 
There are a few problems associated with development of such the model. First of all, a method which should enable to assess the performance of the ro-ro ships in damaged conditions. Working out such the method it should be underlined that the method structure has to be according with the requirements existing within the current regulations (SOLAS 2009), IMO 2008. The next issue is to have a possibility to analyze the impact of all the phenomena appearing during the flooding on the damaged ro-ro ship performance and safety. The last research problem is to evaluate if such the model may be an appropriate and reliable tool to assess the performance and safety of ro-ro ships in damaged conditions at the preliminary stage of design.

Generally, the method of safety assessment of commercial ships in damage conditions including the ro-ro ships is based on the requirements included in the SOLAS 2009 regulations (IMO 2005a, IMO 2005b, IMO 2008). This method is of prescriptive character and generally is based on the experience in ship design and operation of ships. This method seems to be reliable form the practical point of view. It is harmonized and very much devoted for the design purposes. It is difficult to apply this method when operating the ships to support the emergency, evacuation or ship salvage procedures.

The measure of a damaged ship safety in the current regulations is the probability of surviving a collision known as the attained subdivision index $\mathrm{A}$ (IMO 2005, SOLAS 2005, Gerigk 2010, IMO 2014).

The major criteria of the method included in the SOLAS 2009 regulations is the condition (1) (IMO 2005a, IMO 2005b, IMO 2008):

$$
\mathrm{A}>\mathrm{R}
$$

where $\mathrm{A}=$ attained subdivision index calculated for the draughts $d_{s}, d_{p}$ and $d_{1}$ defined in regulation 2, according to the formula (2), IMO (2005):

$\mathrm{A}=\sum \mathrm{p}_{\mathrm{i}} \mathrm{S}_{\mathrm{i}}$

where $p_{i}=$ probability that only the compartment or group of compartments under consideration may be flooded, as defined in regulation $7-1 ; \mathrm{si}=$ conditional probability of ship survival after flooding the compartment or group of compartments under consideration, as defined in regulation $7-2 ; \mathrm{R}=$ required subdivision index given with the regulations.

The probabilities $\mathrm{p}_{\mathrm{i}}$ and $\mathrm{si}$ are calculated according to the well known formulae accepted by IMO, (IMO 2005a, IMO 2005b, IMO 2007). A typical process of safety assessment of a ship in damaged conditions at the design stage is directed to satisfy the criteria (1).

The si conditional probability of ship survival after flooding the compartment or group of compartments under consideration is estimated according to the formulae, IMO (2008):

$\mathrm{Si}=\operatorname{minimum}\left\{\right.$ Sintermediate, $\mathrm{i}$ or $\left.\mathrm{Sfinal}_{\mathrm{i}} \mathrm{Smom}, \mathrm{i}\right\}$ where Sintermediate, ${ }=$ conditional probability of ship survival after flooding the compartment or group of compartments during all the intermediate stages of flooding untill the final stage of flooding and it should be calculated according to the formulae included in regulations, IMO (2008); Sfinal, $=$ conditional probability of ship survival after flooding the compartment or group of compartments during in the final stage of flooding and it should be calculated according to the formulae included in regulations as well, IMO (2008); Smom,i = conditional probability of ship survival after flooding the compartment or group of compartments taking into account the moments following from all the possible impacts of the wind, survival craft, passengers impacts, etc. and it should be estimated according to the formulae included in regulations as well, IMO (2008).

The most important information following from application of the above method to the designers is that this method does not take into account a damaged ship dynamics in waves. According to this method the damage stability parameters as hydrostatics-related data are obtained.

Applying this method in practice the scenarios of flooding concern flooding of all the single watertight compartments and groups of compartments under consideration. The key damaged ship performance data concern the ship damage stability parameters and characteristics obtained for the preliminary, intermediate and final stages of flooding.

The dynamics associated with the flooding process is not considered.

The damaged ship dynamics has a big impact on the performance and safety of the ro-ro ships in damaged conditions. And this is one between the most important reasons why it has been decided to renew the investigations towards developing the model which is briefly introduced in the paper. From the practical point of view such the model may one between the most important tools a ship designer should have in his disposal to improve the safety of ships.

\section{METHOD OF ASSESSMENT OF PERFORMANCE AND SAFETY OF THE RO-RO SHIPS IN DAMAGED CONDITIONS}

Working out the method of assessment of performance and safety of the ro-ro ships in damaged conditions it was assumed that the method should be a kind of performance-oriented risk-based method.

The above method is of non-prescriptive character because any case of compartment flooding may be considered to assess a damaged ro-ro ship performance. It may be treated as a prescriptive method from the formal point of view as the requirements included in the current regulations are taken into account as well.

The proposed method is based on the assumption that the safety assessment of a damaged ro-ro ship should be done according to assessment of the damaged ship performance followed by the risk 
assessment understood as considering all the possible cases of flooding.

Assessment of performance of the damaged ro-ro ship can be done according to estimation of the major characteristics describing the behavior of the ship during the flooding process.

The ship behavior may be described by major features and characteristics of the damaged ro-ro ship like the floatability, damage stability and dynamics of the damaged ship. The latest means that the influence of the preliminary, intermediate, additional (releases) and final events (consequences) of the flooding process are taken into account during assessment of performance of the damaged ro-ro ship.

It was decided that the damaged ro-ro-ship behavior may be presented as the ship motion taking into account three degrees of freedom (3DoF) as follows:

- sway of the damaged ro-ro ship;

- heave of the damaged ro-ro ship;

- roll of the damaged ro-ro ship.

The major components of the damaged ro-ro ship motion are briefly presented in Figure 1.

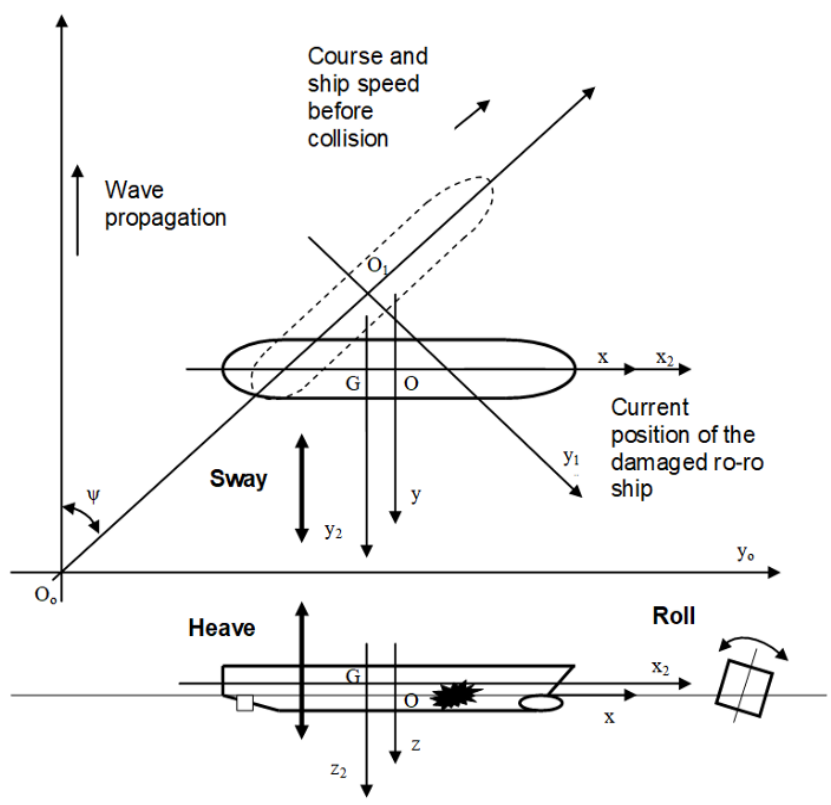

Figure 1. The major components of the damaged ro-ro ship motion (Author: M.K. Gerigk).

Introducing the method of assessment of the damaged ro-ro ships performance it has been assumed that there is a dependence between the arrangement of internal spaces of a ro-ro ship and flooding process. Therefore a criteria is to find the best ro-ro ship subdivision having the smallest impact of the flooding on the damaged ro-ro ship performance and safety.

The major phenomena which have been decided to take into account when considering flooding of the roro ships are as follows:

- flooding is understood as the flow of external water into the data damaged compartment;

- -impact of the flooding water on the ship structure should be understood as the mass, volume, inertia, damping and additional heeling moment following from the flooding water;
- impact of the flooding water on the damaged ro-ro ship motion.

Knowing the damaged ro-ro ship motion characteristics including the sway, heave and roll it is relatively easy to assess which characteristics is the most important form performance of the damaged roro ship point of view.

It has been decided that the heeling angle in time domain will be the roll damage function which describes the damaged ro-ro ship performance in the best way. This heeling angle in time domain characteristics is the main data for assessing the significant value the heeling angle. During the design process this value may be compared with the angle of heel obtained from the damage stability calculations.

The roll damage function (heeling angle in time domain) is the key design driver for assessing the correlation between the ro-ro ship subdivision (arrangement of internal spaces) and flooding. The significant value of the heeling angle of a damaged ro-ro ship is the value compared with the critical angle of heel (safety criteria) included in the current regulations.

The last research issue is to investigate if the proposed model may be appropriate tool for assessing the performance of the ro-ro ships in damaged conditions at the preliminary stage of design.

From the sientific point of view it is important to add that the risk-based design and a formalized design methodology may be integrated together as it was published by Gerigk, Skjong, Vassalos and the Ship Stability and Research Centre in Glasgow (Gerigk 2010, Skjong et al. 2006, SSRC 2009, Vassalos 2006). The proposed method is a kind of performanceoriented risk-based method which enables to assess the safety of ro-ro ships in damaged conditions on the basis of the damaged ro-ro ship performance. Such the approach was introduced by Gerigk and adopted for the current research including the necessary changes concerning the ro-ro ships, Gerigk (2010).

Generally, for assessment of performance of the damaged ro-ro ship either the statistics, investigations using the physical models and numerical simulation techniques may be applied. They may be used all together but such the approach is time consuming and very expensive. The risk assessment may be based on application of the matrix type risk model which is prepared in such a way that it enables to consider almost all the possible scenarios of events during the flooding, Gerigk (2010). It is a big difference in comparison with the fixed set of accident scenarios (flooding) as it is in the current regulations. From the ship safety point of view the criteria is to achieve an adequate level of risk using the risk acceptance criteria, risk matrix or ALARP concept, Gerigk (2010).

Finally, it may be underlined that providing a sufficient level of ship safety based on assessment of damaged ro-ro ship performance and risk assessment is the main objective of the work form the methodology and practical point of view. It is the design objective as the safety is the design objective between the other objectives. 
The measure of performance of a damaged ro-ro ship is the adequate level of the damaged ship characteristics (floatability, damage stability, damaged ship dynamics) enabling avoiding the capsizing and sinking (loss of floatability). The measure of safety of a damaged ro-ro ship is the risk (level of risk).

The general structure of the method of assessment of performance and safety of the ro-ro ships in damaged conditions is presented in Figure 2, Gerigk (2010).

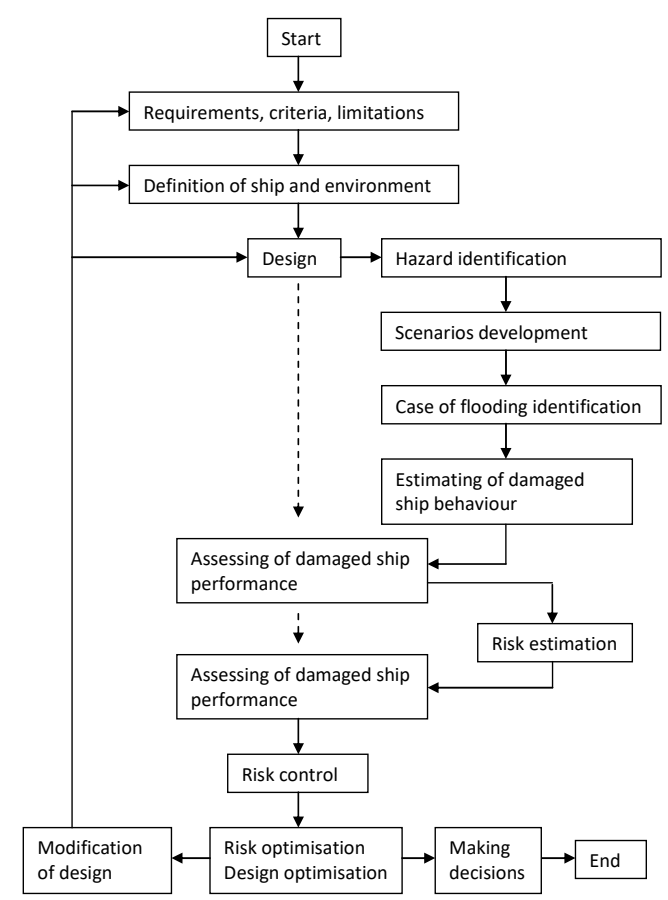

Figure 2. Structure of the method of assessment of performance and safety of the ro-ro ships in damaged conditions (Author: M.K. Gerigk).

The method structure is based on the general structure presented in previous work by Gerigk, Gerigk (2010). But the presented in the paper method is more devoted to the performance assessment problems associated with the safety of ro-ro ships in damaged conditions. It is clear when comparing the structure of the method presented by Gerigk in 2010 and structure of the current method introduced briefly in this Chapter (see Figure 2). The basic elements of the current method are as follows:

- requirements, criteria, limitations, objectives;

- ro-ro ship and environment definition;

- hazards and scenarios identification (cases of ro-ro ship flooding);

- estimation of the damaged ro-ro ship behavior (floatability, damage stability, ship dynamics 3DoF motion);

- assessment of the damaged ro-ro ship performance based on the roll damage function (heeling angel in time domain, heeling angle significant value);

- risk estimation;

- risk assessment (risk matrix, ALARP concept);

- risk management (risk control options);

- selecting the ro-ro ship design that meet the requirements, criteria, limitations, safety objectives;

- optimizing the ro-ro ship design;

- making the decisions on the ro-ro ship safety.
The knowledge on ships safety and methodology of ship safety assessment may be found in the papers given in References (Abramowicz-Gerigk 2006, Abramowicz-Gerigk 2008b, Abramowicz-Gerigk \& Burciu 2013, Arangio 2012, Burciu \& Grabski 2011, Gerigk 2004, Gerigk 2005, Gerigk 2006, Gerigk 2008, Gerigk 2010, Gerigk 2012, Gerigk 2014a, Gerigk 2014b).

\section{MODEL OF FLOODING OF RO-RO SHIPS IN DAMAGED CONDITIONS}

The ship accidents at sea may lead to the loss of life, loss of properties (ship and cargo) and pollution of environment. The modern approach to safety of maritime transportation still requires to apply the new achievements within the ship design for safety domain. The effective assessment of ship performance and ship safety assessment often require to develop the new methods, models and tools. It concerns the methods, models and tools for analyzing the performance and safety of ships in damaged conditions as well.

The current method included in the regulations (SOLAS 2009) introduced in Chapter 1 is a prescriptive method in its character. It is based on the combined approach to assessment of the damaged ship performance and safety. In some cases the semiprobabilistic components are incorporated within the method. The main disadvantage of this method is that it does take into account the fixed set of scenarios (flooding process) without considering the dynamics of flooding. It means that assessment of performance and safety of the damaged ship is only based on assessment of the the damaged ship floatability and damage stability data. Further it means that only static-related data decide about the behaviour of the damaged ship and assessment of the damaged performance (capsizing, sinking). The dynamics associated with the flooding process is not considered in the existing method.

The method presented in Chapter 1 is very difficult to apply to certain types of ships e.g. carcarriers, ro-ro vessels or passenger ships. Using it in these cases it may lead to insufficient level of safety or provide unnecessary design or then operational restrictions.

This is why the aim of this paper is to shown how to incorporate the dynamics of a damaged ro-ro ship for performance assessment of the damaged ro-ro ship (roll damage function, heeling angle in time domain, significant heeling angle) and assessment of safety of the damaged ro-ro ship (capsizing, sinking). Therefore the basic information on the new hybrid model for assessment of performance and safety assessment of the ro-ro ships in damaged conditions including the damaged ro-ro ship dynamics is presented in the paper.

\subsection{Flooding process and floodwater dynamics}

The behavior of a damaged ro-ro ship (motion: heeling angle in time domain) is following from three major mechanisms: 
- flooding process and dynamics of floodwater,

- interaction between floodwater and damaged roro ship,

- damaged ro-ro ship motion in waves.

The flow through the damage (opening or set of openings) is estimated according to the equation which can be obtained from the Bernoulli's equation for the steady flow of water. All the possible phases of flooding (water levels) through the damage opening during the damaged ro-ro ship motion in waves are presented in Figure 3 (Gerigk 2010, Gerigk 2014a, Gerigk 2014b).

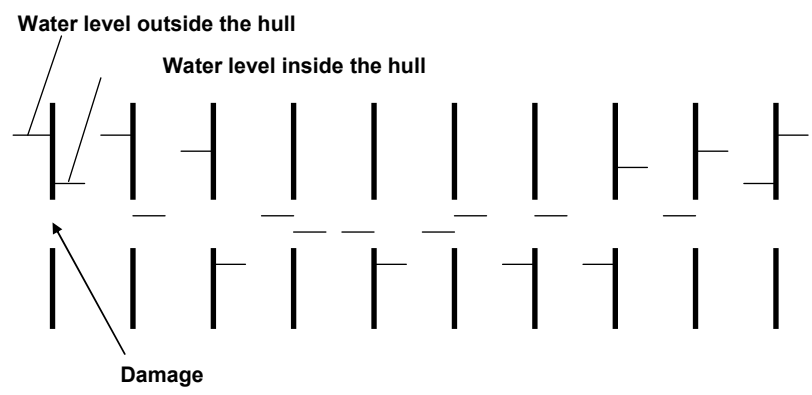

Figure 3. Possible phases of flooding (water levels) through a damage opening (Gerigk, 2010).

\subsection{Interaction between floodwater and ro-ro ship dynamics}

The effect of interaction between floodwater and damaged ro-ro ship motion can be estimated using either the added weight or added force concept. According to the added weight concept, the floodwater should be treated as an added weight with a moving centre of gravity. This changes the location of the ship's overall centre of gravity. The total mass of the ro-ro ship is changed during flooding and therefore the inertia forces should be changed as well. It is assumed that the floodwater does not experience a negative vertical acceleration.

In the case of the added force concept the forces due to the floodwater are treated as external forces. The forces due to floodwater should be calculated using the instantaneous acceleration rather than gravitational acceleration and by integrating the water pressure at the compartment walls (Gerigk 2010, Gerigk 2014a).

There are three methods of modeling the floodwater - damaged ro-ro ship motion interaction as follows, ITTC (2011):

- quasi-static with static floodwater treatment (interaction: added weight);

- quasi-dynamic with dynamic floodwater treatment (interaction: added weight);

- dynamic with dynamic floodwater treatment (interaction: added force).

The floodwater dynamics can be predicted using various models ranging from the second order ordinary differential equations through to numerical fluid mechanics (CFD).

Taking into account the modeling of floodwater ro-ro ship motion interactions it has been decided to use at this stage of research the quasi-static model. Obtaining the promising results of assessment of a damaged ro-ro ship performance using this model it may be decided to apply the quasi-dynamic model after that. In such a way it is possible to compare the behavior of the damaged ro-ro ship applying both the models of the floodwater-ship motion interactions.

The excitation accumulated flood water forces should be calculated according to the following assumptions: water in the flooded compartment moves in the quasi-static way and free surface of water in the flooded compartment is flat and moves in different way depending on the model.

An example of the floodwater - ship interactions in the case of the quasi-static model with the horizontal free surface is presented in Figure 4, ITTC (2011). In the case of the quasi-dynamic model the free surface in the flooded compartment is not horizontal. It is flat and changing according to the ship motions in each time step.

\subsection{Damaged ro-ro ship motion in waves}

Generally, the 2-D strip method or 3-D panel method may be used to calculate the radiation elements within the equations of damaged ship motion together with the direct integration used to calculate the non-linear restoring forces. In some cases the damaged ship motion is considered in 6DoF (six degrees of freedom) domain. During the presented studies it is assumed to use the 3DoF domain: sway, heave and roll. The roll viscous dumping is added by the use of empirical formulae. The linear memory effect function (added mass and wave damping) may be used even for the large amplitude motion and heeling condition The particular solutions may be found in literature (Dudziak 2008, Faltinsen 1990, Gerigk 2010).

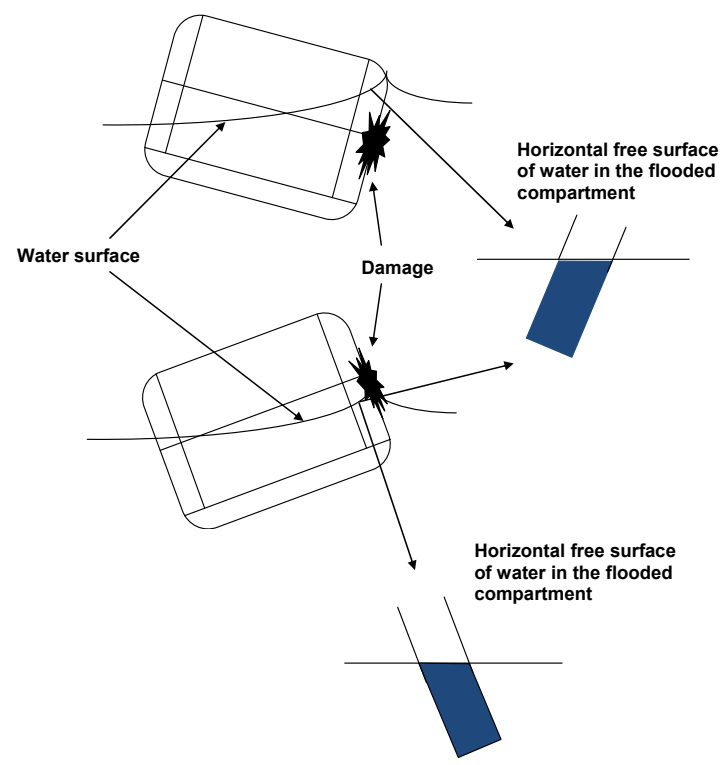

Figure 4. The graphical interpretation of the quasi-static model with the horizontal free surface of water in the flooded compartment, (Gerigk 2010, Gerigk 2014a).

Assessing the performance of a damaged ship the following impacts may be taken into account:

- gravitational forces, 
- hydrostatic forces,

- excitation Froude-Krylov forces,

- excitation diffraction forces,

- accumulated flood water forces,

- cargo shift forces.

\section{PRELIMINARY RESULTS USING THE METHOD AND MODEL}

The ship accidents at sea may lead to the loss of life, loss of properties (ship and cargo) and pollution of environment. The modern approach to safety of maritime transportation still requires to apply the new achievements within the ship design for safety domain. The effective assessment of ship performance and ship safety assessment often require to develop the new methods, models and tools. It concerns the methods, models and tools for analyzing the performance and safety of ships in damaged conditions as well.

It seems that the presented method of performance and safety assessment of ships in damage conditions enables to analyze almost for all the possible accident scenarios (flooding) including the preliminary, intermediate and final stages of flooding. What is more important the method and model enable to take into account both the statics and dynamics towards assessing the performance and safety (risk) of a damaged ship (ro-ro ship as a design case).

Such an approach to ship safety assessment in damage conditions is necessary to predict any further deterioration of the damage condition. As an example, if the ship survives flooding and is unable to return to port under own power it is necessary to solve the problems associated with the towing when waiting for an assistance. During the towing the risk and safety assessment of the ship should be permanently controlled (Perera \& Soares Guedes 2011, Skjong \& Vanem \& Rusas \& Olufsen 2006, Soares Guedes \& Teixeira 2001). The structure of the entire procedure for the assessment of safety of ships in abnormal/damage conditions during the accident at sea and for the salvage purposes was published by Gerigk, (Gerigk 2010, Gerigk 2012).

The preliminary implementations of the method and model itself have been done for two different models of ro-ro ships.

The first model is based on a ro-ro ship shape box of the dimensions as follows: length: $\mathrm{L}=25.0$ meters; breadth: $\mathrm{B}=17.0$ meters; height: $\mathrm{H}=12.0$ meters. The basic information on the ro-ro ship shape box is presented in Figure 5.

During the preliminary assessment of performance of the ro-ro ship shape box in damage conditions the following results of identification of the angle of heel (using a quasi-static approach) according to the data values of the wing tank height and breadth (printed as " $h "$ and "b" in Figure 6) were obtained as follows (areas from the right to the left in Figure 5: from 80 to 100 degrees, 60-80 degrees, 40-60 degrees, 20-40 degrees and 0-20 degrees.

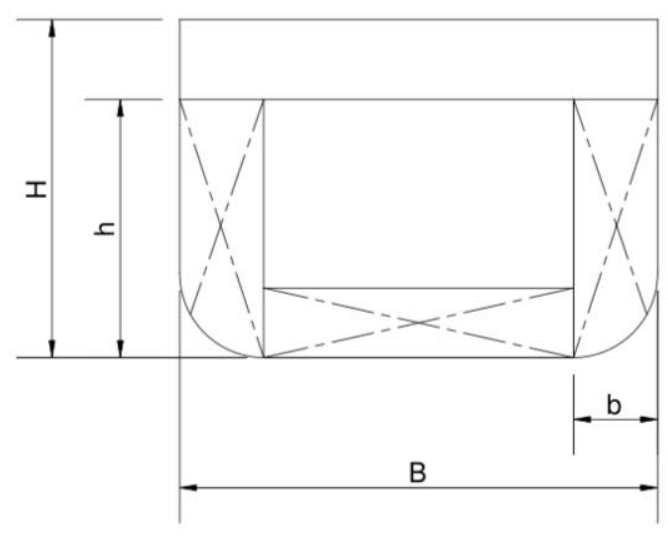

Figure 5. The hull form of the ro-ro ship shape box

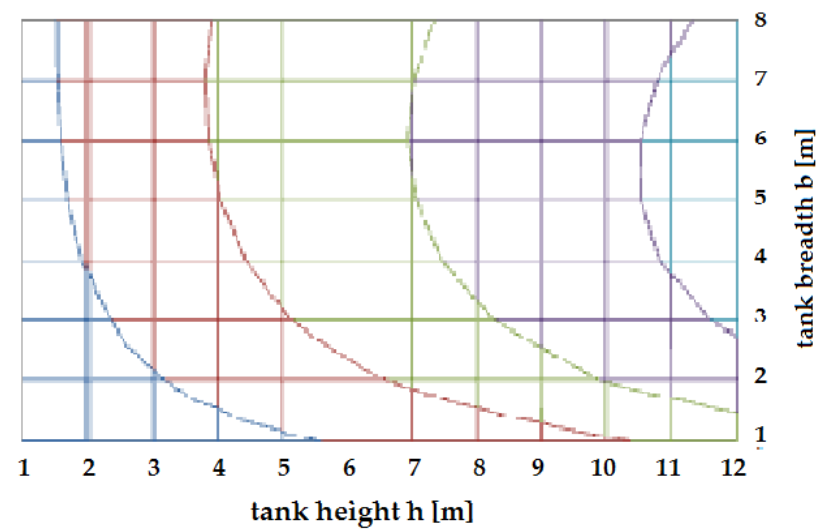

Figure 6. The results of identification of the angle of heel according to the values of the wing tank height " $h$ " and wing tank breadth " $b$ " of the ro-ro ship shape box (Author: J. Sargun).

The second model is based on a ro-ro ferry ship shape box of the dimensions as follows: length: $\mathrm{L}=2.0$ meters; breadth: $\mathrm{B}=0.4$ meters; height: $\mathrm{H}=0.25$ meters. The basic information following from the physical model investigations of the ro-ro ferry ship shape box is presented in Figure 7, (Gerigk 2010, Gerigk 2014a).

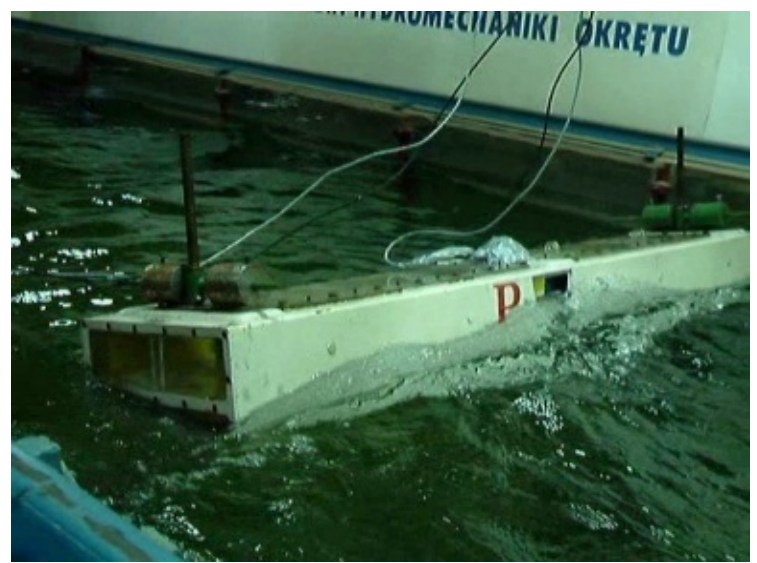

Figure 7. The physical model investigations of the ro-ro ferry ship shape box (Gerigk, 2010).

Some results obtained using the physical model investigations of the ro-ro ferry ship shape box as the angle of heel in time domain are of a stochastic character. They vary very much depending on the initial and boundary conditions during the 
investigations. An example of results in the form of the heeling angle in time domain are presented in Figure 8. The vertical axis regards the angle of heel and the horizontal axis concerns the time in seconds. These results were obtained for the data as follows:

- wave height equal to $\zeta_{\mathrm{w}}=0.06 \mathrm{~m}$ and wave length to model length ratio equal to $\lambda_{w} / L_{s}=0.3$, (Gerigk 2010, Gerigk 2014a, Gerigk 2014b).

\section{Roll damage function}

Heellng angle [degrees] In time domaln (x-axis) [seconds]

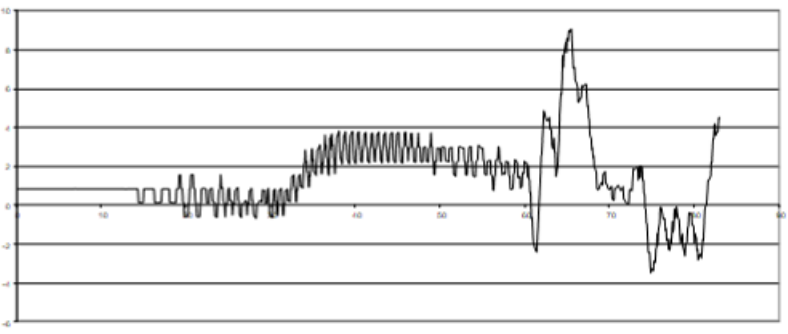

Figure 8. An example roll damage function as the angle of heel of the ro-ro ferry ship shape box physical model in time domain obtained during the investigations at the Faculty of Ocean Engineering and Ship Technology Gdańsk University of Technology (Gerigk, 2010).

Generally, about thirteen performance/safety functions may be used considering each sequence of events during flooding of a ro-ro ship in damaged conditions. Between these functions are as follows, Gerigk 2010: avoiding the hazard, hull skin damage (flooding), position and extension of damage, equalization of the ship heel at the preliminary stage of flooding, loss of the ship stability at the preliminary stage of flooding, loss of the ship stability during the intermediate stages (and phases) of flooding, loss of the ship stability at the final stage of flooding, loss of the ship floatability at the final stage of flooding, ship is waiting for assistance, ship returns to port under own power, ship returns to port by tow, ship is continuing the mission, fire and/or explosion.

\section{CONCLUSIONS}

Some information on the method and hybrid model for assessment of performance and safety assessment of ships (design case: ro-ro ships) in damaged conditions is presented in the paper.

The key issue to apply the method is to have an adequate model for performance assessment of the ships in damaged conditions. Some elements of such the model called a hybrid model is presented in the paper. The model is under construction and is prepared for identification of the behavior characteristics of a damaged ship including floatability, damage stability and damaged ship dynamics (angle of heel in time domain). At this moment the model is prepared to three major degrees of freedom (3DoF) including the sway, heave and roll. It is decided to use the quasi-static model for estimating the behavior of a damaged ship (angle of heel in time domain). To do this three major problems should be solved: flooding process and dynamics of floodwater, interaction between floodwater and damaged ship and damaged ship motion in waves.
The key design driver for the performance and safety assessment of a ro-ro damaged ship is the roll damage function (angle of heel in time domain).

This function seems to be one between the most important characteristics of a damaged ro-ro ship.

From the practical point of view, at the preliminary design stage, the roll function enables the designer to assess how much time the flooding last from the preliminary to the final stage of flooding. This function enables the design to predict the extreme and significant values of the heeling angle during the flooding including estimating the time a captain may has in his disposal to start the emergency and evacuation procedures. The entire information concerning the roll damage function may be included with a ship stability booklet.

The current research concerns further development of the hybrid model of flooding of the ro-ro ships in damaged conditions. The final results will be published according to a Ph.D. procedure of J. Sargun to be accomplished at the Faculty of Mechanical Engineering Gdańsk University of Technology.

\section{ACKNOWLEDGEMENTS}

Some information presented in the paper was prepared during a project conducted at the Gdańsk University of Technology between 2006-2007. The authors would like to express their thanks to the former Ministry of Science and Higher Education (MNiSzW) for supporting the research. The project was founded by the MNiSzW Ministry according to the agreement No. N509 008 31/0584. The project title was "Alternatywna metoda oceny bezpieczeństwa statku w oparciu o ocenę ryzyka".

\section{REFERENCES}

Abramowicz-Gerigk T., Burciu Z., 2014. Safety assessment of maritime transport - Bayesian risk-based approach in different fields of maritime transport. Proceedings of IMAM 2013, 15th International Congress of the International Maritime Association of the Mediterranean (IMAM), Spain. Developments in Maritime Transportation and Exploitation of Sea resources. Guedes Soares \& Lopez Pena (eds), Volume 2, 2014 Taylor\&Francis Group, London, UK, p. 699-703.

Abramowicz-Gerigk T. 2005. Investigation on Standards for Ship Manoeuvring Performance at Slow Speed in Constrained Space. in C. Guedes Soares, Y. Garbatow \& N. Fonesca (eds.), Maritime Transportation and Exploitation of Ocean and Coastal Resources. Vessels for Maritime Transportation. Proceedings of the 12th International Congress of the International Maritime Association of the Mediterranean (IMAM'2005), Lizbona, Portugalia 2005, Vol.1: 3-8. London, Balkema.

Abramowicz-Gerigk T. 2006. Determination of Safety Factors for Ship Berthing Operations. Proceedings and Monographs in Engineering, Water and Earth Sciences. Proceedings of the European Safety and Reliability Conference 2006 (ESREL 2006), Volume 3, Estoril, Portugal, 18-22 September 2006, Published by Taylor \& Francis / Balkema, London / Leiden / New York / Philadelphia / Singapore, 2737-2742.

Abramowicz-Gerigk T. 2008a. Experimental study on the hydrodynamic forces induced by a twin-propeller ferry 
during berthing. Ocean Engineering. Elsevier. Vol. 35, Issues 3-4, March 2008: 323-332.

Abramowicz-Gerigk T. 2008b. The risk analysis of harbour operations. in S. Martorell, C. Guedes Soares \& Julie Barnet (eds.) Safety Reliability and Risk Analysis: Theory, Methods and Applications. Proceedings of the ESREL 2008 and 17th SRA-Europe Conference, Valencia, Vol. 4: 3343-3350, London: Balkema.

Arangio, S., 2012. Reliability based approach for structural design and assessment: performance criteria and indicators in current European codes and guidelines. International Journal of Lifecycle Performance Engineering, $1(1)$, p.64.

Burciu, Z. \& Grabski, Fr. 2011. The experimental and theoretical study on the reliability of the life rafts. Reliability Engineering and System Safety 96: 1456-146.

Dudziak J., 2008. The theory of ships (in Polish: Teoria okrętu), The Foundation of Promotion of the Shipbuilding and Marine Economy (in Polish: Fundacja Promocji Przemysłu Okrętowego i Gospodarki Morskiej), Gdańsk 2008.

Faltinsen O.M.,1990. Sea Loads on Ships and Offshore Structures, Cambridge University Press, 1990.

Gerigk M., 2004. On a risk-based method for safety assessment of a ship in critical conditions at the preliminary design stage. Polish Maritime Research, No. 1 (39), Vol. 11, p. 8-13

Gerigk M. 2005. Challenges of modern assessment of safety of ships in critical conditions. Proceedings and Monographs in Engineering, Water and Earth Sciences. Proceedings of the 12th International Congress of the International Maritime Association of the Mediterranean IMAM 2005, Volume 2, Lisboa, Portugal, 26-30 September 2005, Published by Taylor \& Francis / Balkema, London / Leiden / New York / Philadelphia / Singapore, 1529-1536.

Gerigk M. 2006. A method for assessing hazards, risks and safety of damaged ships at sea. Proceedings and Monographs in Engineering, Water and Earth Sciences. Proceedings of the European Safety and Reliability Conference 2006 (ESREL 2006), Volume 3, Estoril, Portugal, 18-22 September 2006, Published by Taylor \& Francis / Balkema, London / Leiden /New York / Philadelphia / Singapore, 2783-2790.

Gerigk M. 2008. Modeling of hazards, consequences and risk for safety assessment of ships in damaged conditions in operation. Proceedings and Monographs in Engineering, Water and Earth Sciences. Proceedings of the European Safety and Reliability Conference, ESREL 2008 and 17th SRA-Europe, Volume 4, Valencia, Spain, 22-25 September 2008, Published by CRC Press, Taylor \& Francis Group, Balkema, Boca Raton/London/New York/Leiden, 3303-3310.

Gerigk M.K., 2010. A complex method for assessment of safety of ships in damage conditions using the risk analysis (in Polish: Kompleksowa metoda oceny bezpieczeństwa statku $\mathrm{W}$ stanie uszkodzonym $\mathrm{Z}$ uwzględnieniem analizy ryzyka), Monography No. 101 (in Polish: Monografie 101), Edited by the Gdańsk University of Technology (in Polish: Wydawnictwo Politechniki Gdańskiej), Gdańsk 2010.
Gerigk M., 2012. Assessment of safety of ships after the collision and during the ship salvage using the matrix type risk model and uncertainties. in Sustainable Maritime Transportation and Exploitation of Sea Resources. Proceedings of the 14th International Congress of the International Maritime Association of the Mediterranean (IMAM), Volume 2: 715-719, London: Balkema.

Gerigk M.,2014a. Quantitative risk assessment of new ship designs in damaged conditions. Proceedings of the European Safety and Reliability Conference, ESREL 2014, Wrocław, Poland, 14-18 September 2014, Taylor \& Francis Group, London, UK, ISBN: 978-1-138-02681-0 $(\mathrm{Hbk}+\mathrm{CD}-\mathrm{ROM})$.

Gerigk M. 2014b. Modeling of event trees for the rapid scenario development. Proceedings of the European Safety and Reliability Conference, ESREL 2014, Wrocław, Poland, 14-18 September 2014, Taylor \& Francis Group, London, UK, ISBN: 978-1-138-02681-0 (Hbk + CD-ROM).

IMO, 2005. Report of the Maritime Safety Committee on Its Eightieth Session. MSC 80/24/Add.1, London, 2005.

IMO. 2008. http://www.imo.org.

IMO. 2009. Stability and Seakeeping Characteristics of Damaged Passenger Ships in a Seaway When Returning to Port by Own Power or Under Tow, A survey of residual stability margin, Submitted by Germany, SLF 52/8/1, London, 26 October 2009.

ITTC. 2011. The specialist Committee on Stability in Waves. Final Report and Recommendations to the 26th ITTC, Proceedings of 26th ITTC - Volume II, Rio de Janeiro, Brasil, 28 August - 3 September, 2011.

ITTC. 2011. ITTC - Recommended Procedures and Guidelines. Numerical Simulation of Capsize Behaviour of Damaged Ships in Irregular Beam Seas, 7.5-02-07-04.4, Proceedings of 26th ITTC - Volume II, Rio de Janeiro, Brasil, 28 August - 3 September, 2011.

Jasionowski A. 2011. Decision support for ship flooding crisis management, Ocean Engineering, Volume 38, Issues 14-15, October 2011, Pages 1568-1581.

Papanikolaou A., Hamann R., Lee B.S., Mains C., Olufsen O., Vassalos D., Zaraphonitis G., 2013. GOALDS-Goal Based Damage Ship Stability and safety standards, Accident Analysis \& Prevention, Volume 60, November 2013, Pages 353-365.

Perera L.P. \& Soares Guedes C. 2011. Detections of potential collision situations by relative motions of vessels under parameter uncertainties, Proceedings of the $14^{\text {th }}$ International Congress of the International Maritime Association of the Mediterranean (IMAM), Genova, Italy, 13-16 September 2011.

Skjong, R. \& Vanem, E. \& Rusas, S. \& Olufsen, O. 2006. Holistic and Risk Based Approach to Collision Damage Stability of Passenger Ships, Proceedings of the $9^{\text {th }}$ International Conference on Stability of Ships and Ocean Vehicles STAB 2006, Rio de Janeiro, 25-29 September 2006.

Soares, C.G. \& Teixeira, A.P., 2001. Risk assessment in maritime transportation. Reliability engineering and System Safety, 74, pp.299-309.

SOLAS, 2005. International Convention for the Safety of Life at Sea. Lloyd's Register Rulefinder 2005 - Version 9.4., pp. $1-910$.

SSRC. 2009. http://www.ssrc.na-me.ac.uk 